\title{
Palabras del Maestro Maurizio Governatori, autor del monumento "La Mano de la Paz"
}

Saludos a todos los presentes, a las autoridades de esta Universidad, al Vicepresidente de la República Omar Halleslevens por estar presente en este evento, un saludo en particular a la Rectora Doctora Lidya Ruth Zamora, quien fue la primera persona que miró el proyecto y se comprometió totalmente, al Vicerrector, Reverendo Msc. Tomas Téllez, y ex Rector, Ingeniero Emerson Sandoval.

Un saludo a mi amiga Rosario Pasquier Luna, egresada de la Escuela de Derecho de la UPOLI, que me ha hospedado durante estos dos meses.

Un abrazo al equipo de trabajo el Maestro Sócrates Martínez y su esposa Nenci, al Maestro Salvador Gutiérrez, al maestro Sergio Serrano al soldador Juan Francisco Ponce. Y a los trabajadores que se comprometieron por la realización de esta obra.

\section{La mano por la Paz}

La mano aqui representada viene a sugerir la voluntad, el trabajo y el amor por la paz. Ahora, ahora, ahora la necesitamos con urgencia.

La idea de esta escultura se produce un día observando a mi nieto al mar, mientras que jugando en la orilla con las cáscaras, tuve la percepción de la inocencia de sus manos, un momento de pura belleza.

Al mismo tiempo pensé que estas manos un día más inocente en los años podría convertirse en la mano violenta. Al vivir este contraste me surge la idea de dar una respuesta, por lo tanto, la mano de un adulto, consciente, de trabajadores que optan por la paz y trabajar por ello.
Las palomas son el resultado de la desfragmentación creativa del dedo índice, como generador de una nueva vida, pura, amable, solidaria. Pensando a Miguel Ángel en la Capilla Sixtina.

Se trata de una escultura utópica, pero como dice Galeano no se puede prescindir de la utopía.

La mano tambien, como escribí en un artículo publicado en Italia, no es sólo una herramienta de trabajo, alimenta el desarrollo, la experiencia, y la inteligencia, es la mano que hizo al hombre.

"Pensar fuera del cuerpo es como el arte sin la mano, sin aquella sensibilidad que nos permita pensar totalmente. Esta relación entre el cuerpo, la mano, la mente, ha hecho posible el desarrollo de los pensamientos y las artes, la mano como un medio de conocimiento y avance de la humanidad.

¿Qué progreso, la humanidad habría aterrizado si los pensamientos que el hombre ha sido capaz de desarrollarse mentalmente, permanecieron pensamientos sin manos?".

Es el contacto que hace que un cuerpo sea real, St. Thomas quería tocar con el fin de contar con información completa, no sólo imagenes sino el contacto con el cuerpo como verdadera en las formas reales.

Esta mano, entonces que tenemos delante no es sólo una herramienta de trabajo, es un pensamiento de la mano que decide y elege estar en paz, ella decide quedarse humana, no violenta.

Para concluir, pido a los presentes, ponerse de pie para hacer un minuto de silencio, por los niños de Palestina a quienes dedico esta obra. 